\title{
Optimization of parameters of the bearing structures of deep excavations with minimization of environmental impacts
}

\author{
Pavel Morozovskiy ${ }^{1, *}$, Anna Babanina ${ }^{1}$, Kristina Ziiaeva ${ }^{1}$ and Sergey Shulzhenko ${ }^{2}$ \\ ${ }^{1}$ Peter the Great St.Petersburg Polytechnic University, Polytechnicheskaya, 29, St. Petersburg, \\ 195251, Russia \\ ${ }^{2}$ Moscow State University of Civil Engineering, Yaroslavskoe shosse, 26, Moscow, 129337, Russia
}

\begin{abstract}
The aim of the project is optimizing the parameters of deep foundation pits in order to improve their technical efficiency and economic feasibility, and development of an optimization algorithm. The analysis is carried out using the program complex PLAXIS 2D 2011. The article considers a model of the foundation pits to a depth of 5-20 m with various settings of attachment. To study the work of the soil body, the MohrCoulomb model is used as the simplest and strengthening soil with a small strain as the most reliable.
\end{abstract}

\section{Introduction}

Construction of pits is always associated with significant financial costs, the value of which is directly or indirectly associated with the adopted design decisions. The financial efficiency of construction is primarily influenced by the decisions made at the design stage.

Plaxis is a software system of finite-element analysis, used for solving problems geotechnical engineering and designing, is a package of computational programs for finite element calculation of stress-strain state of structures, foundations and bases. As a result of the study, the influence of the soil behavior model on the final values in the calculation of various parameters was established. The parameters of numerical models were selected to provide a reliable idea of the processes taking place in the soil mass. The impact of construction on the soil body was estimated by: displacement of the wall in the ground; internal stresses in the wall; settling of the soil in the vicinity of the foundation pit; lifting the bottom of the foundation pit [1].

\subsection{Model of linear-elastic medium (Elastic)}

The mechanical model of the linearly deformable medium based on the theory of elasticity is widely used in engineering practice and will be used for a long time in the design of mass construction. In addition, it can be used to estimate, in the first approximation of strain-stress state, soil arrays serving as bases for heavy and unique structures, with subsequent adjustment

\footnotetext{
*Corresponding author: morozovoff85@gmail.com
} 
by means of more complex calculations. A linear relationship between stress and deformation in a soil medium is valid for small ranges of stress changes and deformations. This range depends on the density-moisture content, granulometric composition of soil, its output of stress-state state, etc. And a linear relationship holds when offloading, but with other modules.

\subsection{Mohr-Coulomb theory (M-C)}

Mohr-Coulomb theory is a mathematical model describing the response of brittle materials such as concrete, or rubble piles, to shear stress as well as normal stress. Most of the classical engineering materials somehow follow this rule in at least a portion of their shear failure envelope. Generally the theory applies to materials for which the compressive strength far exceeds the tensile strength.

\subsection{Hardening soil model (HS)}

The Hardening Soil model is an advanced model for the simulation of soil behaviour. As for the Mohr-Coulomb model, limiting states of stress are described by means of the friction angle phi, the cohesion $\mathrm{c}$ and the dilatancy angle psi. However, soil stiffness is described much more accurately by using three different input stiffnesses: the triaxial stiffness E50, the triaxial unloading stiffness Eur and the oedometer loading stiffness Eoed. In contrast to the Mohr-Coulomb model, the Hardening Soil model also accounts for stress-dependency of stiffness moduli. This means that all stiffnesses increase with pressure. Hence, all three input stiffnesses relate to a reference stress, usually taken as $100 \mathrm{KPa}(1 \mathrm{Bar})$.

Besides the model parameters mentioned above, initial soil conditions, such as preconsolidation, play an essential role in most soil deformation problems. This can be taken into account in the initial stress generation [2-5]. The question of comparison of results when using different groundwater models, including HS, have been studied by many engineersgeotechnical [6-14]. Foreign researchers have carried out a comparison of calculations performed in several soil models with the results of field vane test [15-18].

\subsection{Hardening soil with small strain model (HS Small)}

Hardening Soil-small (HS-small) models are designed to reproduce basic phenomena exhibited by soils: densification, stiffness stress dependency, plastic yielding dilatancy, strong stiffness variation with growing shear strain amplitude in the regime of small strains $\left(\gamma=10^{-6}\right.$ to $\left.\gamma=10^{-3}\right)$.

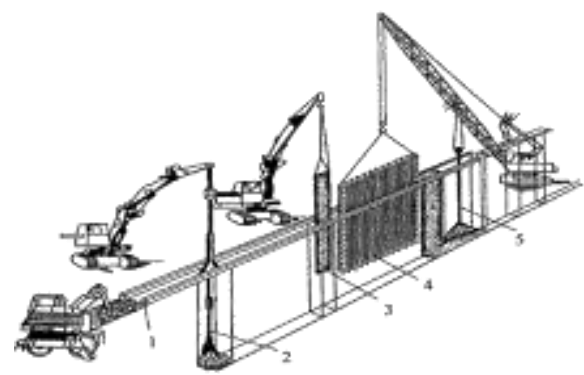

Fig. 1. Top-down technology ( 1 - collar wall,2 - digging the trench for the length of the work zone, 3 - set limiters (jumpers between work zones, 4 - installation of reinforcement cages, 5 - concreting at work zone with tremie method of concreting). 


\section{Calculation basic data}

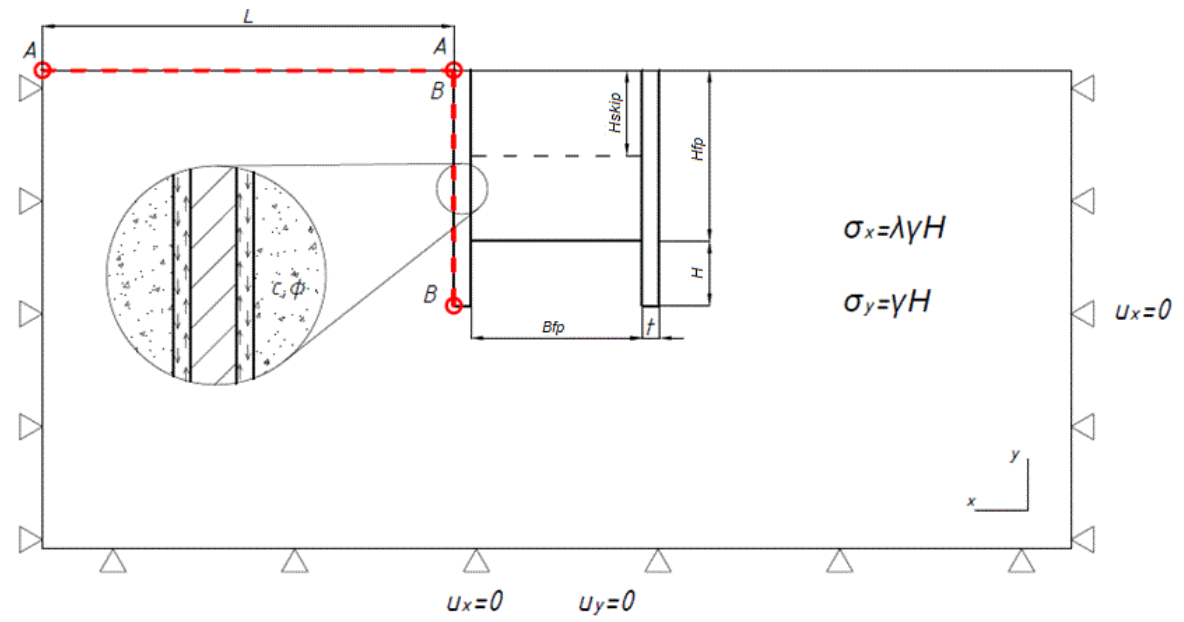

Fig. 2. Analytical model.

\section{Basic data:}

$5 \times 5 \mathrm{~m}$ - size of foundation pit;

Thick of wall $-0.5 \mathrm{~m}$;

Skip deep - $2.5 \mathrm{~m}$;

Summary wall deep $-10 \mathrm{~m}$;

Soil type - sand.

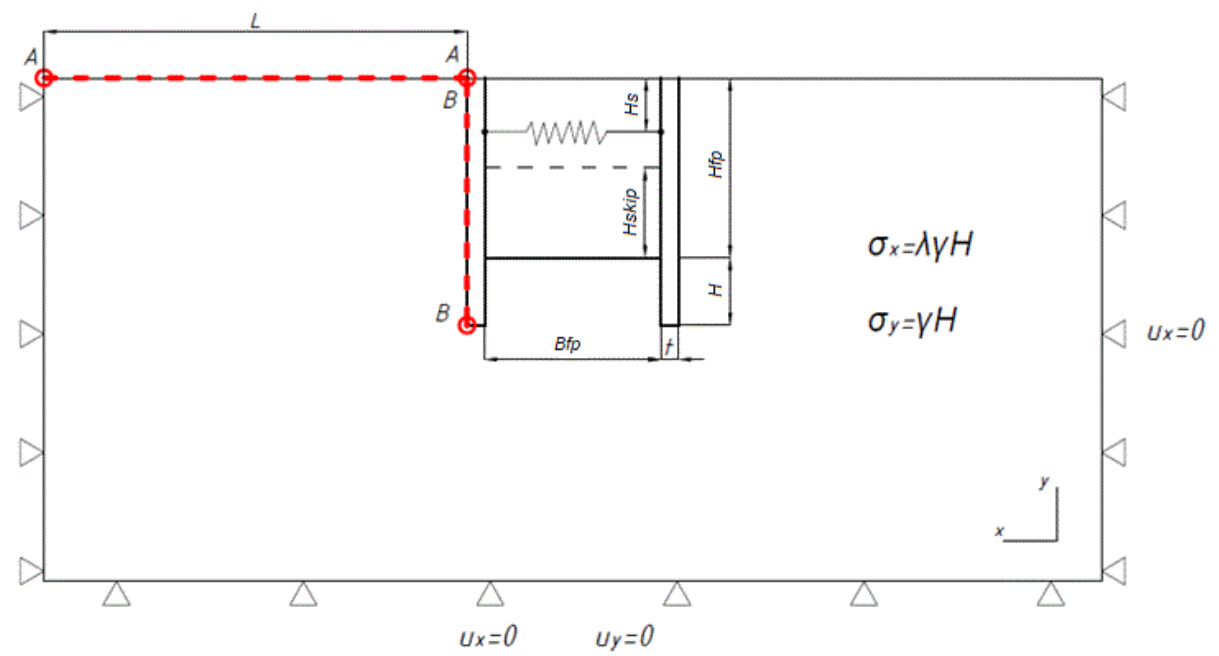

Fig. 3. Analytical model with applying stull-set system.

\section{Basic data:}

$5 \times 5 \mathrm{~m}$ - size of foundation pit;

Thick of wall $-0.5 \mathrm{~m}$;

Skip deep - $2.5 \mathrm{~m}$;

Summary wall deep $-10 \mathrm{~m}$;

Soil type - sand;

Stull-set system with a diameter of $0,5 \mathrm{~m}$ is established at a depth of $1,5 \mathrm{~m}$ from an edge. 
Table 1. Basic soil data.

\begin{tabular}{|c|c|c|c|c|c|c|c|c|c|c|c|c|c|c|c|c|}
\hline & 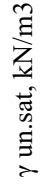 & 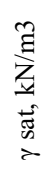 & $\sum_{i=1}^{\pi}$ & 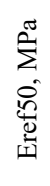 & 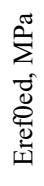 & 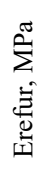 & $\Xi$ & $\frac{\pi}{0}$ & $\hat{\theta}$ & $\stackrel{\circ}{\xi}$ & $>$ & 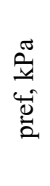 & 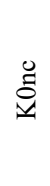 & $\breve{\sim}$ & 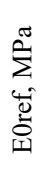 & $\stackrel{0}{2}$ \\
\hline $\begin{array}{c}\text { Model of } \\
\text { linear-elastic } \\
\text { medium }\end{array}$ & $\stackrel{\infty}{\sim}$ & iి & $m$ & ' & ' & ' & ' & ' & ' & ' & $\stackrel{+}{0}$ & ' & ' & ' & ' & ' \\
\hline $\begin{array}{l}\text { Mohr- } \\
\text { Coulomb } \\
\text { model }\end{array}$ & $\stackrel{\infty}{\sim}$ & त् & $m$ & ' & ' & ' & ' & $\overrightarrow{0}$ & $m$ & $\nabla$ & $\stackrel{+}{0}$ & ' & ' & ' & ' & I \\
\hline $\begin{array}{l}\text { Hardening soil } \\
\text { model }\end{array}$ & $\stackrel{\infty}{\sim}$ & $\stackrel{\sim}{\text { ( }}$ & ' & $\stackrel{n}{n}$ & $\stackrel{n}{m}$ & $\stackrel{n}{\varrho}$ & $\tilde{0}$ & $\overrightarrow{0}$ & $m$ & $\nabla$ & กี & 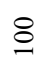 & $\stackrel{?}{\circ}$ & $\hat{o}$ & ' & , \\
\hline $\begin{array}{l}\text { Hardening soil } \\
\text { with small } \\
\text { strain model }\end{array}$ & $\stackrel{\infty}{\sim}$ & 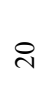 & ' & $\stackrel{m}{m}$ & $\stackrel{n}{m}$ & $\stackrel{\varrho}{\varrho}$ & $\tilde{n}$ & $\overrightarrow{0}$ & $m$ & $\nabla$ & ขี & 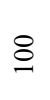 & $\stackrel{?}{\stackrel{f}{0}}$ & $\hat{o}$ & $\underset{\substack{\infty \\
+\infty}}{ }$ & 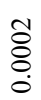 \\
\hline
\end{tabular}

\section{Results and Discussion}

The calculation results of soil and wall displacements are shown in the figures 4-9 hereinafter.

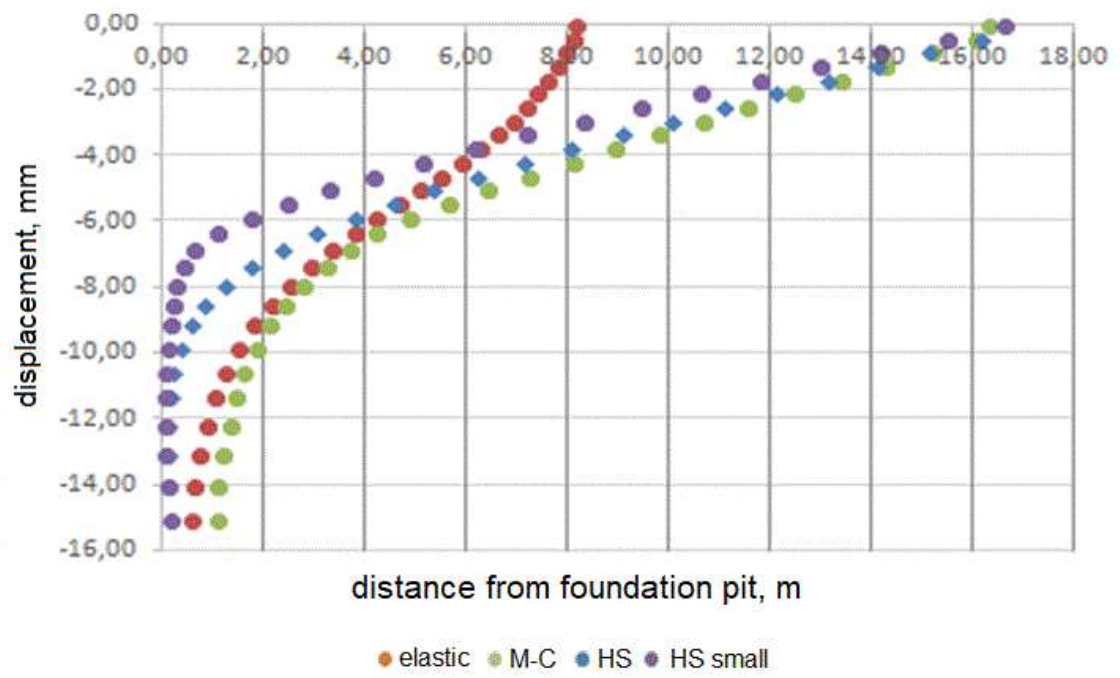

Fig. 4. Displacement of the wall according to the distance from the foundation pit. 


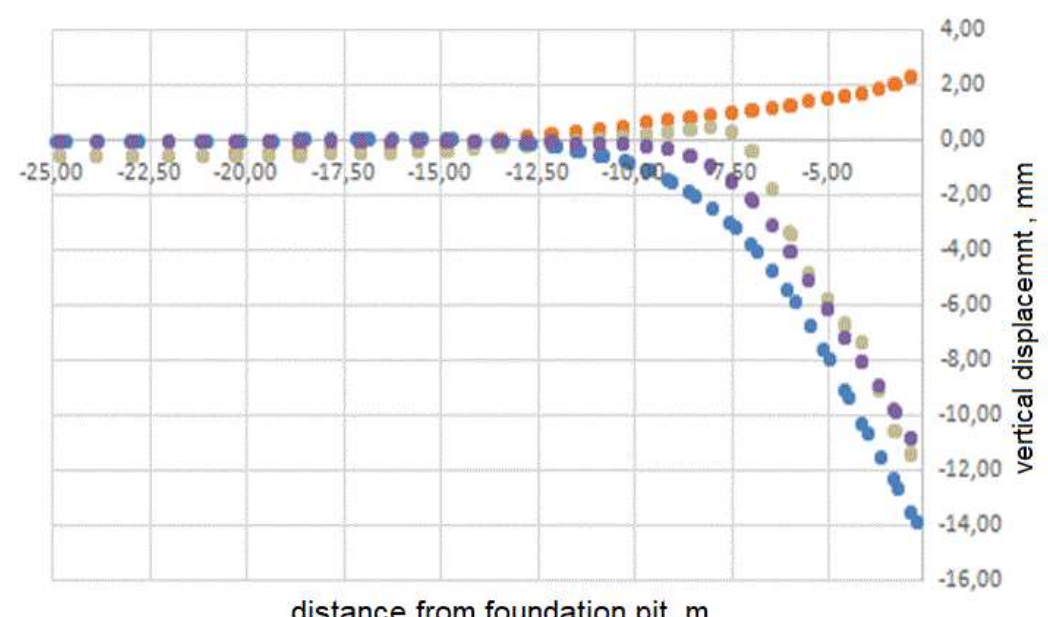

distance from foundation pit, $\mathrm{m}$

- elastic $\oplus \mathrm{M}-\mathrm{C} \bullet \mathrm{HS} \bullet \mathrm{HS}$ small

Fig. 5. Vertical displacement of soil according to the distance from the foundation pit.
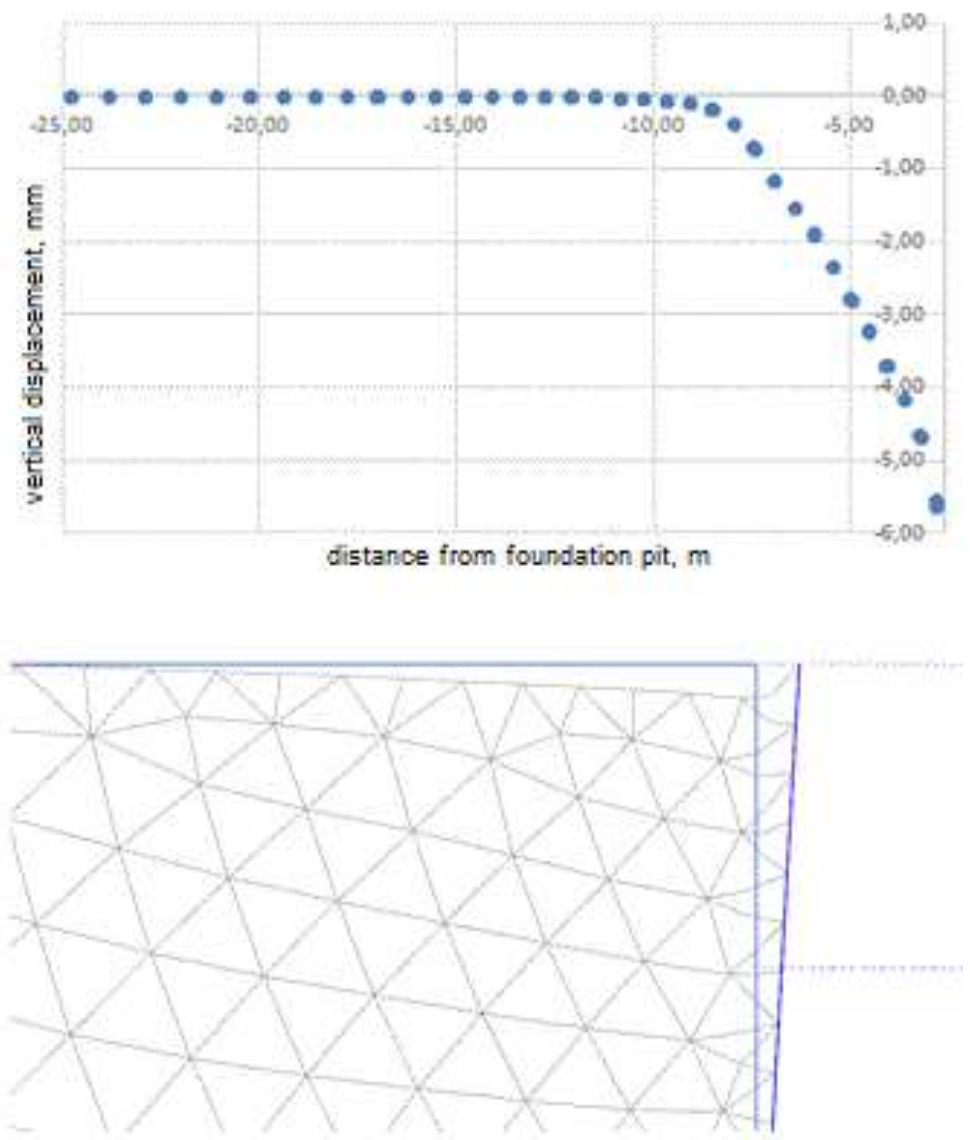

Fig. 6. Without contact weakening. 


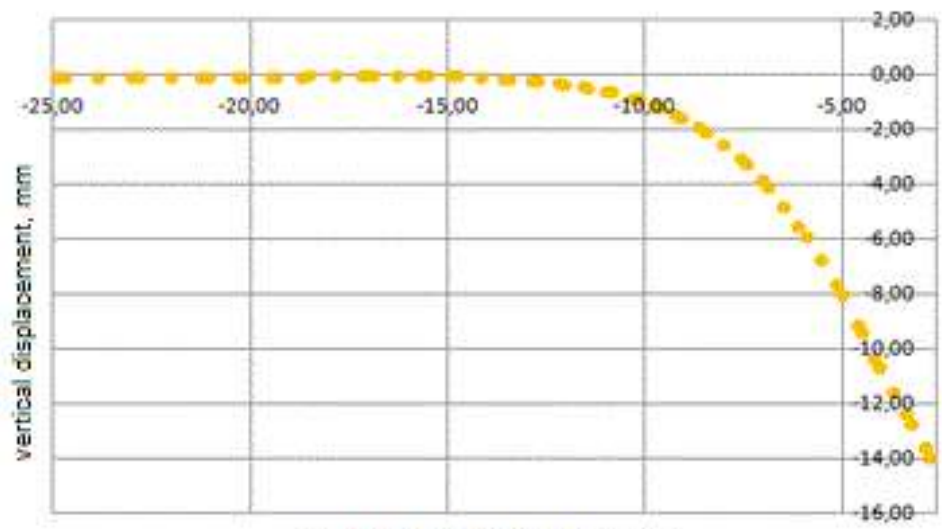

distance from foundation pit, $m$

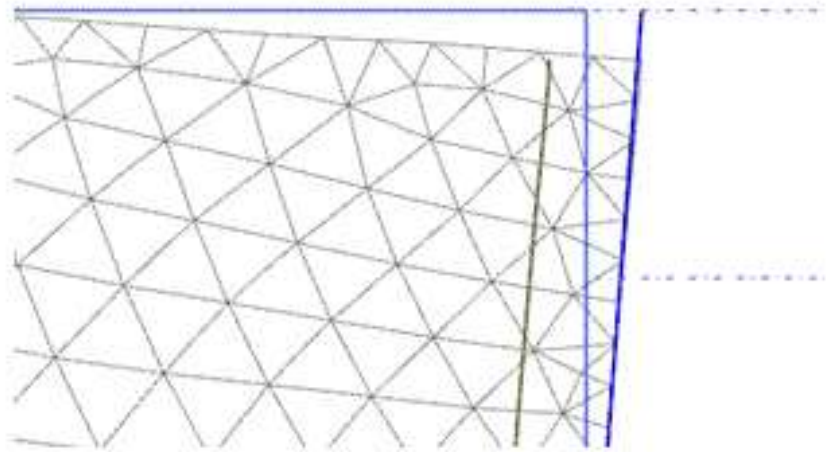

Fig. 7. With contact weakening.

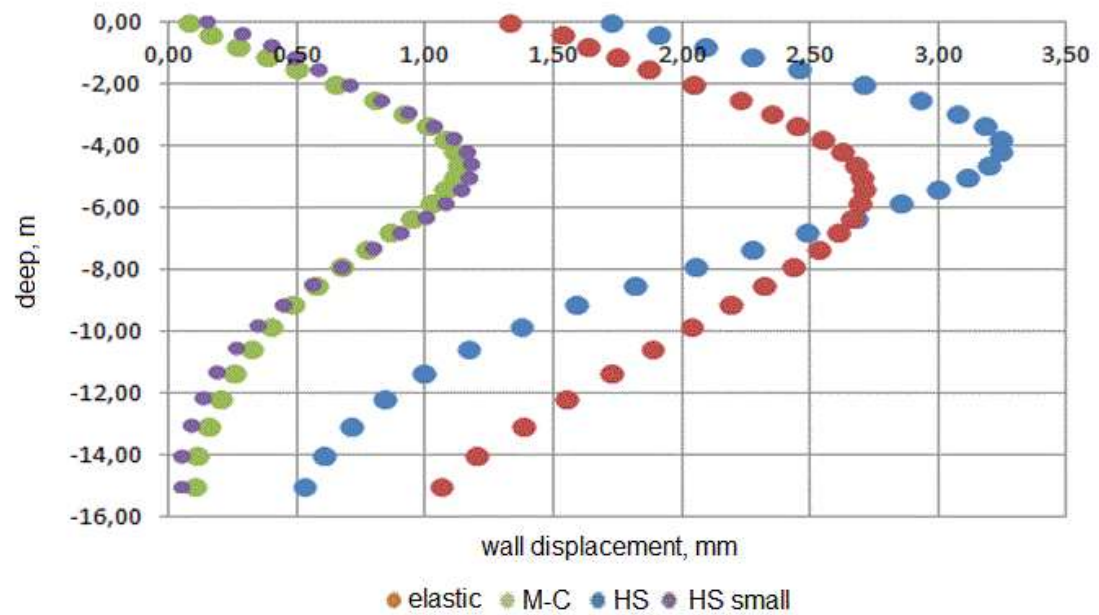

Fig. 8. Wall horizontal displacement diagram (stull-set system). 


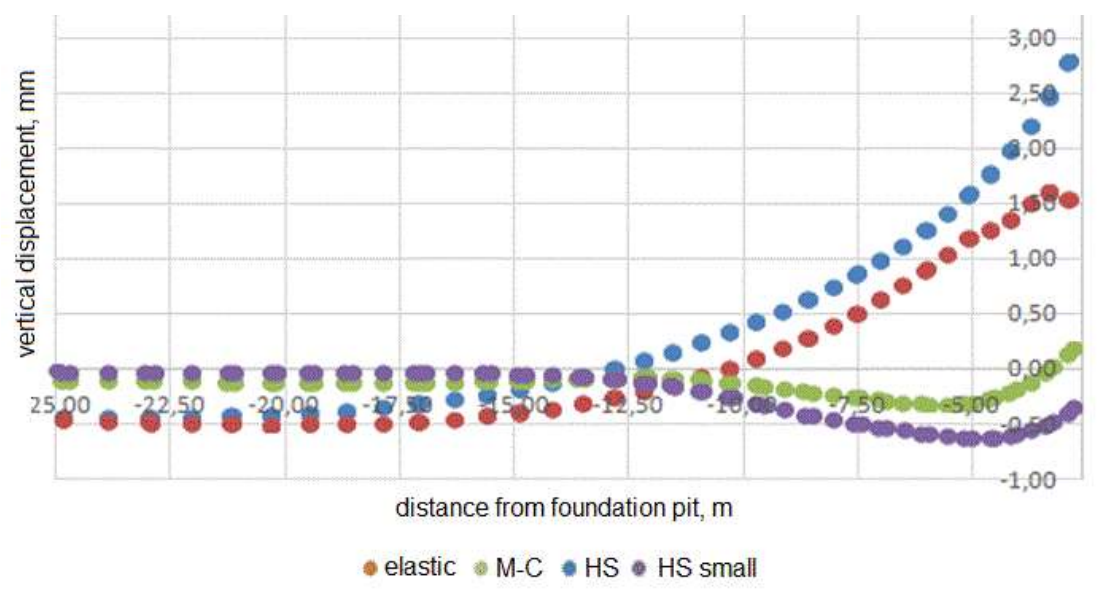

Fig. 9. Soil vertical displacement diagram (stull-set system).

Based on the results obtained, the following conclusions can be drawn:

elastic model requires a minimum amount of time to get results. It does not allow quantitative and qualitative assessment of the state of the structure and the soil body; not recommended for practical calculations;

elastic-plastic Mohr-Coulumb model can be used in case of insufficient number of physical and mechanical characteristics of soils. It works only at low loads and strains;

elastic-plastic models with soil hardening allow to obtain the most reliable results of soil deformation in the vicinity of the structure, which positively affects the correctness of the forecast of efforts in the elements of enclosing and supporting structures. You need a large amount of data.

\section{Conclusions}

Thus, the influence of the numerical model on the calculation results was revealed and the optimal calculation model for further research - hardening soil with small strain-was chosen.

After the choice of the calculation model, such design parameters as the thickness of the top-down method wall, the magnitude of the fixing, the stiffness of the cross braces were considered.

The thickness of the wall was also analyzed (in relative terms, with an increase in the value to the optimum, it is possible to reduce the settlements by almost 2 times); the rigidity of the cross brace structures (to a lesser extent affects the resulting precipitation), and the optimal value of the fixing by the factor for the three variants of the installation of cross braces at the depth of the wall was found out that it is most appropriate to install the cross brace at the lower part of the wall, this makes it possible to significantly reduce the amount of penetration and as a consequence the consumption of materials).

The diagram below shows the results of the analysis of the influence of the value of fixing the walls of the soil settlement in the vicinity of the pit. The unit adopted the maximum value of precipitation is when the value of fixing, equal to the pit depth. 


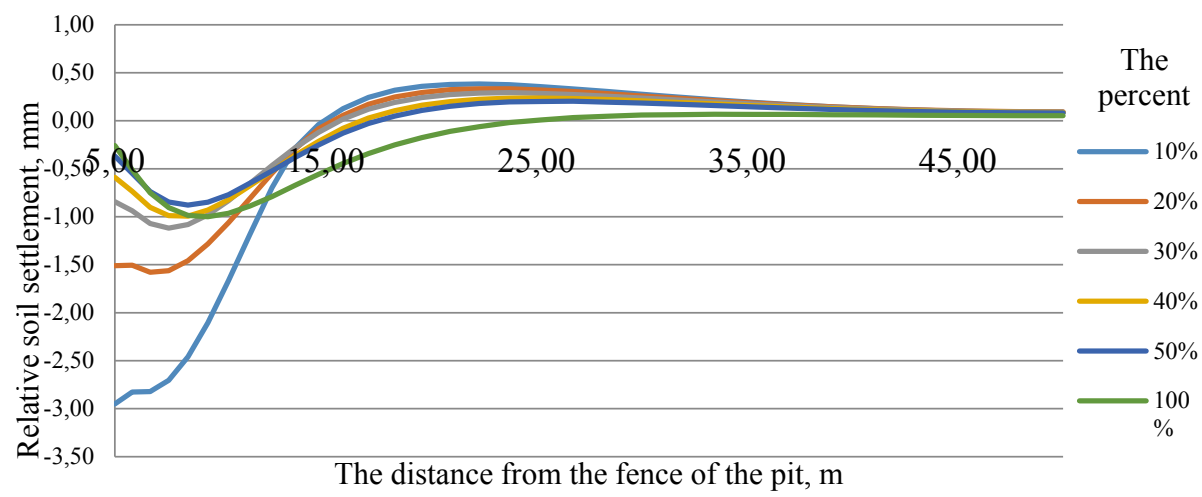

Fig. 10. Influence of the value of fixing the walls of the soil settlement.

In the same way, the influence of the wall thickness and the stiffness of the cross braces was analyzed. The results are presented in the following diagrams.

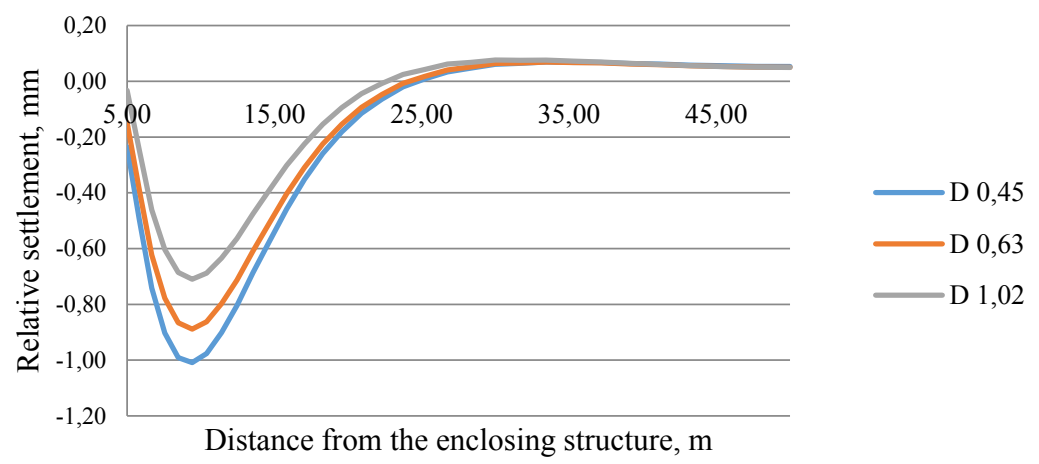

Fig. 11. Influence of the wall thickness and the stiffness of the cross braces.

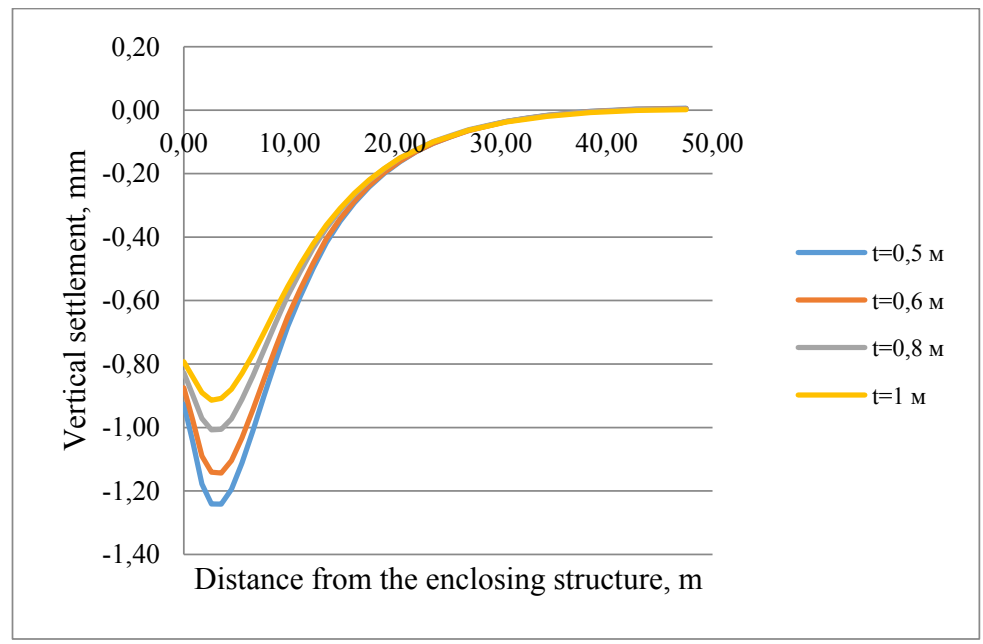

Fig. 11. Influence of the wall thickness and the stiffness of the cross braces. 
As a result of the analysis it was revealed that at this object there is a possibility of achieving economic and temporary effect due to the reduction of the thickness of the enclosing structure - the Top-Down method wall, as well as increasing the step of cross braces, without significant changes in the deformation of the surrounding rock mass. In particular, it is proposed to reduce the thickness of the Top-Down method wall from $1.0 \mathrm{~m}$ to $0.8 \mathrm{~m}$, as well as to increase the step of cross braces in the center of the ceilings from 6 to $12 \mathrm{~m}$.

The adopted final parameters of fixing the walls of the deep pit allow to meet all the requirements set by the regulatory documents for the design of deep pits, both in terms of the stress state of the support and the permissible deformations of the earth's surface.

The proposed solution made it possible to reduce the total duration of construction of a deep pit by 1.5 months, the cost of construction by 278.7 million rubles.

\section{References}

1. A. B. Fadeyev, Metod konechnykh elementov v geomekhanike [Finite element method in geomechanics]. Moscow: Nedra, (1987)

2. https://www.plaxis.com/support/models/hardening-soil-model/ (Last accessed 14.03.2019)

3. T. Shanz, P. A. Vermeer, P. G. Bonnier, The hardening soil model: Formulation and verification. Beyond 2000 in Computational Geotechnics - 10 years of Plaxis

4. K. V. Slivets, Opredeleniye vnutrennikh parametrov modeli Hardening Soil Model [Definition of the internal parameters of Hardening Soil Model]. Geotekhnika, 6 (2010)

5. A. B. Fadeyev, Parameters of Hardening Soil Model realised in program PLAXIS (in Russian) (Saint-Petersburg, SPbGASU. 2012)

6. V. N. Paramonov, Experimental verification of the adaptability of some soil models for calculation of retaining walls, 4, (in Russian) (Vestnik Tomskogo gosudarstvennogo arkhitkturno-stroitelnogo universiteta, 2008)

7. A. A. Garkavko, Construction solutions of deep excavation support suystems. Master's thesis (in Russian) (Saint-Petersburg: SPbGPU, 2011)

8. V. N. Paramonov, Experimental verification of the adaptability of some soil models for calculation of retaining walls, 4 (in Russian) (Vestnik Tomskogo gosudarstvennogo arkhitkturno-stroitelnogo universiteta, 2008)

9. K. V. Slivets, Investigation of retaining walls developed in silty and clayey soils. $\mathrm{PhD}$ theis (Saint-Petersburg, 2009)

10. F. Aggogeri, A. Borboni, A. Merlo, N. Pellegrini, Machine tools thermostabilization using passive control strategies, Advanced Materials Research, 590, pp. 252-257 (2012) DOI: 10.4028/www.scientific.net/AMR.590.252

11. K. E. Sherstyanykh, Ground-anchor fencing of excavation support. Master's thesis. (in Russian) (Saint-Petersburg: SPbGPU, 2011)

12. M. A. Bezgadov, S. V. Kaloshina, Selecting a soil model for computational modeling of the influence of deep excavation on existing buildings, 2, (in Russian) (Vestnik PNIPU. Urbanistika, 2012)

13. I. V. Kolybyn, Experience of emergency accidents during the excavations in urban conditions. Razvitiye gorodov i geotekhnicheskoye stroitelstvo, 12 (in Russian) (2008) 
14. D. Yu. Chunyuk, V. F. Yarnykh, Reducing geotechnical risks in construcrion on the example of calculation and design of deep excavations in cramped conditions megacities, 2, (in Russian) (Vestnik MGSU, 2009)

15. T. Benz, R Schwab, P. A. Vermeer, On the practical use of advanced constitutive laws in finite element foundation analysis. Fondsup 2003 International Symposium. (2003)

16. C. Wiltafsky, F. Scharinger, H. F. Schweiger, Results from a geotechnical benchmark exercise of an embankment on soft clay. International Workshop on Geotechnics of Soft Soils-Theory and Practice (2003)

17. S. J. Wheeler, M. Cudny, H. P. Neher, C. Wiltafsky, Some developments in constitutive modeling of soft clays. International Workshop on Geotechnics of Soft Soils-Theory and Practice (2003)

18. R. B. J. Brinkgreve, Selection of sil models and parameters for geotechnical engineering application. Soil Constitutive Models: Evaluation, Selection, and Calibration. Ed. J.A.Yamamuro, V.N.Kaliakin. American Society of Civil Engineers, 128 (2005) 